\title{
Mechanism of Strain Burst by Laboratory and Numerical Analysis
}

\author{
Manchao He, ${ }^{1}$ Fuqiang Ren $\mathbb{D},{ }^{1,2}$ and Cheng Cheng ${ }^{3}$ \\ ${ }^{1}$ State Key Laboratory for Geomechanics \& Deep Underground Engineering, Beijing 100083, China \\ ${ }^{2}$ School of Mechanics and Civil Engineering, China University of Mining \& Technology, Beijing 100083, China \\ ${ }^{3}$ Institute of Geology and Geophysics, Chinese Academy of Sciences, Beijing 100029, China \\ Correspondence should be addressed to Fuqiang Ren; xq1050211@163.com
}

Received 23 May 2018; Revised 13 July 2018; Accepted 26 July 2018; Published 23 October 2018

Academic Editor: Francesco Franco

Copyright (C) 2018 Manchao He et al. This is an open access article distributed under the Creative Commons Attribution License, which permits unrestricted use, distribution, and reproduction in any medium, provided the original work is properly cited.

\begin{abstract}
Strain burst is often considered to be a type of failure related to brittle rock material; therefore, many studies on strain burst focus on the brittleness of rock. However, the laboratory experiments show that strain burst can not only occur in hard brittle rock-like granite but also in the relatively ductile rock-like argillaceous sandstone. This result proves that behavior of rock material is not the only factor influencing the occurrence of strain burst. What must also be considered is the relative stiffness between the excavation wall/ore body and the surrounding rock mass. In order to further studying the mechanism of strain burst considering the whole system, the engineering geomechanial model and numerical model of strain burst due to excavation are built, respectively. In a series of numerical tests, the rock mass involving the excavation wall as well as roof and floor is biaxially loaded to the in situ stress state before one side of the excavation wall is unloaded abruptly to simulate the excavation in the field. With various system stiffness determined by the microproperties including the contact moduli of particles and parallel bond moduli in the models of roof and floor, the different failure characteristics are obtained. Based on the failure phenomenon, deformation, and released energy from the roof and floor, this study proves that the system stiffness is a key factor determining the violence of the failure, and strain burst is prone to happen when the system is soft. Two critical Young's moduli ratios and stiffness ratios are identified to assess the violence of failure.
\end{abstract}

\section{Introduction}

Hoek [1] mentioned that "Rockbursts are explosive failures of rock which occurs when very high stress concentrations are induced around underground openings. The problem is particularly acute in deep level mining in hard brittle rock." And "A characteristic of almost all rockbursts is that they occur in highly stressed, brittle rock." Strain burst is often considered as a violent failure closely related to the hard brittle rock due to excavation, and many researches focus on the mechanical behavior of the rock material-like brittleness: the ratio of uniaxial compressive strength to tensile strength of rock was applied by Zhang et al. [2] and Khanlari and Ghaderi-Meybodi [3], as well as $Q_{1}=\left(\sigma_{\mathrm{c}}-\sigma_{\mathrm{t}}\right) /\left(\sigma_{\mathrm{c}}+\sigma_{\mathrm{t}}\right)$ and $Q_{2}=\sin \varphi$ have been employed by Singh [4], while $Q_{u}=$ $\left(u_{1}+u_{2}\right) / u_{1}$ by Tan [5] to assess the violence of rock burst, where $\sigma_{\mathrm{c}}$ and $\sigma_{\mathrm{t}}$ are the uniaxial compressive and tensile strengths, respectively; $\varphi$ is the frictional angle of the rock; and $u_{1}$ and $u_{2}$ are the permanent and elastic axial deformation of the rock specimen in a loading-unloading cycling uniaxial test.

Hucka and Das [6] concluded some observations associated with higher brittleness involving low values of elongation, fracture failure, formation of fines, high ratio of compressive to tensile strength, high resilience, and large angle of internal friction and formation of cracks in indentation. Rock brittleness is defined by Andreev [7] as the ability of a rock material to deform continuously and perpetually without apparent permanent deformations along with the application of stress surpassing the necessary stresses for microcracking of the material. On the contrary, Handin [8] defined ductility as the ability to undergo large permanent deformation without fracture. Apparently, strain burst does not belong to the ductile behavior, and at the meantime, it is not simply a conventional brittle failure, as strain burst happens around an excavation in a sudden or violent manner, associated with the excess energy from the 
surrounding rock mass, and may lead to rock bulking, ejection, etc. Brittleness cannot cover the nature of strain burst, and there should be some other factors determining the energy release and violence of strain burst.

The in situ stress and the excavation-induced stress lead to the strain energy stored in the rock mass, which may result in the failure of rock and may supply the excess energy for the strain burst. Meanwhile, strain energy will also be stored in the surrounding rock mass due to the abovementioned stresses and may release when the rock fails and become a source of the excess energy if the stiffness of the surrounding rock mass is relatively low compared with the failing rock. Sometimes, the seismic events owing to collapse, blast, or fault slip near the tunnel may also supply the excess energy to form a violent failure. The excess energy from the surrounding rock mass due to the low system stiffness is the focus in this work.

Cook [9] increased the stiffness of the testing machine by loading a steel tube and carried out the uniaxial compressive tests on the specimens of Tennessee marble and St. Cloud granite. He mentioned that rock burst could be regarded as a stability problem similar to the behavior of the rock specimen in a lab test, i.e., whether the specimen will fail violently or not depend on the relative stiffness between the sample and loading system. Based on the complete stressstrain curve obtained by the stiff test machine, Salamon [10] discussed the relationship between the stability of the specimen and the system stiffness in the perspective of energy and equilibrium in detail and expanded this relationship to the stability of pillar workings. Blake [11] also pointed out that if the rock structure is stiffer than the loading system, the strain energy stored in the loading system will load the rock structure further suddenly when failure happens and causes the occurrence of rock burst and studied the stability of the stope pillar at Galena Mine based on this knowledge. Hedley [12] mentioned the energy driving the rock burst to happen. Aglawe [13] demonstrated that system stiffness, stress level, and released energy are the three important parameters that must be considered together to assess the unstable failure. Similar discussions on the system stiffness and rock burst or violent failure can also be found in many studies [14-17].

The theory based on system stiffness helps us understand more about the mechanism of strain burst; however, up to date, it is not easy to be practical in the field due to the complex geological conditions. Numerical tools have been employed to assess the stability of the underground excavation considering the system stiffness in many studies. Brady and Brown [14] studied the stability of the pillars with different width/high ratios and different spans of the adjacent stopes based on boundary element analysis. The mine local stiffness and pillar stiffness were calculated according to the load-convergence relationship in the numerical models, and the postfailure stiffness of the pillars was obtained from published empirical relationship between the elastic/postpeak stiffness ratio and width/height ratio determined from field and lab tests on rock specimens. Numerical method combining the techniques of both finite element and boundary element were employed by Simon et al. [18] to analyze the stability of a cut-and-fill stope. The Hoek-Brown failure criterion was applied in the model to identify the area that may become unstable (safety factor $<1.0$ ) firstly, and then the mine local stiffness was calculated based on the stress and convergence in the model, as well as the postpeak stiffness of the pillar was obtained with an empirical equation involving a modified brittle index. The studies above are only based on the basic theory of stiffness comparison, but the mutual effect of the pillar and surrounding rock mass could not be analyzed directly in the continuum models which are limited when analyzing the problem of rock failure.

Kaiser and Tang [19] used RFPA models to study the failure process, stress-strain response, seismic events, and seismic energy release during the laboratory uniaxial compression tests and field pillar failure considering different system stiffness. This paper just tested a few conditions of various system stiffness and did not give a critical value for violent failure. Aglawe and Prataprao [13] studied the stability of a single opening with the FLAC model. The results show that the system stiffness determines the nature of the failure process, the stress level and the releasable energy define the potential and the violence of the failure, and the stress level and system stiffness should be considered together to assess the violence of failure process. This work also analyzed the factors influencing the system stiffness. However, this study used an elastic continuum model to research failure problems; what is more, the author only considered the stiffness of the surrounding rock mass while omitted the stiffness of the failure slab. Kias et al. [17] employed three different numerical tools to carry out uniaxial compression tests with variable platen stiffness and obtained the corresponding system response, including the stress-strain behavior of the specimen and loading system, while did not give the failure modes or process.

With a series of laboratory strain burst experiments on different rock types and numerical tests (by particle flow code) considering various system stiffness of the surrounding rock mass, this paper will give some discussion on the mechanism of strain burst and assessment on the violence of strain burst in a perspective of the complete system.

\section{Laboratory Experiments on Strain Burst}

2.1. Experimental System. The laboratory strain burst experiments [20] are conducted with the deep rock burst test system developed in China University of Mining and Technology, Beijing. This experimental system is composed of the main machine, hydraulic controlling, and data acquisition equipment. The main machine is a true triaxial compressive apparatus in which one surface of the prismatic specimen can be unloaded abruptly to simulate the excavation in the field. This feature helps this system have the function to obtain the strain burst phenomenon in the laboratory, and a series of tests [21] have been conducted to study the burst behavior and mechanism.

2.2. Strain Burst Experiments and Discussions. Two types of rock, granite and argillaceous sandstone, have been applied 
to conduct the strain burst tests. The mechanical properties and micromineral contents of the two rock types are listed in Tables 1 and 2. The granite from a quarry in Laizhou, Shandong Province, has a higher uniaxial compressive strength and Young's modulus and lower content of clay mineral. The argillaceous sandstone [22] from Xingcun Coal Mine, Shandong Province, has a lower strength, Young's modulus, and higher content of clay mineral.

The samples of the two types of rock with the nominal dimensions of $150 \mathrm{~mm} \times 60 \mathrm{~mm} \times 30 \mathrm{~mm}$ have been prepared for the strain burst tests. In both tests, the specimens were loaded to a true triaxial stress state and then one side was unloaded suddenly to simulate the excavation. At the meantime, the vertical stress was increased to simulate the stress concentration due to the opening. If failure does not occur in 15 minutes after unloading, the unloaded surface would be reloaded and the sample would be applied to a higher true triaxial stress state and stay for another 15 minutes. The process of unloading and reloading would be repeated until the failure occurs. Figure 1 shows the stresstime curves of the tests on the two types of rock.

Strain burst occurred on the granite after the first unloading and showed a violent failure. Figure 2 exhibits the process of the burst captured by a high-speed camera. At first, crack propagation and spalling were observed on the unloading surface, followed by a buckling and two slices of fragments as well as some particles ejection. At the end, a complete failure happened on the full surface with large amounts of fragments ejecting violently with loud noise. The bursting process [22] of the argillaceous sandstone is presented in Figure 3. Failure mainly happened on the top of the specimen, and lots of fragments ejected with high speed. The argillaceous sandstone failed at a higher peak strength comparing with the granite, and as an explanation, it may be owing to the different loading paths.

Strain burst happens on both the granite and argillaceous sandstone samples, which means that not only the hard brittle rock but also relatively ductile rock may burst. The key factor is whether the loading system, corresponding to the surrounding rock mass in the field, is soft enough compared with the rock material in the area where failure may occur. This result accords with the points mentioned in Section 1 that the unstable failure is related to the relative stiffness between the surrounding rock mass (corresponding to the loading system in the laboratory test) and the excavation wall/ore body (corresponding to the specimen in the laboratory test). The burst of argillaceous sandstone in this study shows that the test machine is soft enough for this type of rock.

However, although strain burst occurs on both rock types, it can be found that the granite fails more violently than the argillaceous sandstone. The reason is as follows: as the test machine is the same, the stiffness of the loading system is the same. But comparing the hard brittle granite with the relatively ductile argillaceous sandstone, the former specimen is suffering relatively softer system and higher strain energy release than the latter one.

It proves that the relationship between the stiffness of the loading system and the rock specimen, i.e., the stiffness of the surrounding rock mass and the excavation or ore body in the field, is a key factor of strain burst intensity. A series of tests considering different system stiffness should be carried out to make clear this relationship to guide the field opening and support. As it is not financially possible to change the stiffness of the test machine for many times, and it is not easy to control the stiffness of the specimen due to the complexity of the rock material, it is very difficult to conduct a group of laboratory strain burst experiments to complete this study. However, the numerical test can overcome the shortcomings mentioned above. A series of numerical tests with particle flow code (PFC) will be carried out in the next sections.

\section{Numerical Tests on Strain Burst}

3.1. Engineering Geological Model and Geomechanical Model. Usually, the surrounding rock mass near an underground opening may involve different types of rock strata with various stiffness, as schematically illustrated in the engineering geological model in Figure 4. During the excavation and stress redistribution on the surrounding rock mass, different amounts of strain energy will be stored and then will be released when the excavation wall fails, which can lead to distinct types of failure around the opening.

In Figure 4, it is assumed that the roof and floor have the same stiffness $K_{\mathrm{e}}$, and the rock stratum which will be excavated has the stiffness of $K_{\mathrm{r}}$. Theoretically, the stiffness ratio $\left(K_{\mathrm{e}} / K_{\mathrm{r}}\right)$ may influence the energy release and violence of failure after excavation. However, how does this ratio influence the failure characteristics and what is the critical value for the violent failure?

The geomechanical model presented in Figure 4 has been built based on the engineering geological model to study the problem described above. In this plane strain problem, the rock mass involving various rock strata suffers vertical and horizontal stress before excavation, and the horizontal stress on one side of a rock stratum is removed to simulate the excavation, while both the roof and floor are still be confined.

Based on the engineering geological model and geomechanical model, the numerical model was built and a series of numerical strain burst tests with various parameters were carried out.

\subsection{Numerical Model}

3.2.1. Selection of the Numerical Method. The continuous and discontinuous numerical methods both were used to simulate the rock failure [23]. When simulating the broken rock masses, it is not easy to say whether the former or the latter is superior. The main difference between the two methods is that the contact between the blocks or particles remains unchanged in the continuous method. The contact between blocks or particles in a discontinuous method requires continuous operation and renewal using the principle of contact mechanics. For the discontinuous method, the fracture in the rock mass allows large-scale 
TABLE 1: Mechanical properties of the granite and argillaceous sandstone.

\begin{tabular}{lccc}
\hline Rock type & UCS $(\mathrm{MPa})$ & Young's modulus $(\mathrm{GPa})$ & Poisson's ratio \\
\hline Granite & 165 & 66.7 & 0.33 \\
Argillaceous sandstone & 125 & 39.1 & 0.36 \\
\hline
\end{tabular}

TABLE 2: Microcomponents of the samples by X-ray diffraction analysis.

\begin{tabular}{lcccccccc}
\hline \multirow{2}{*}{ Sample } & \multicolumn{4}{c}{ Mineral components and contents (\%) } & \multicolumn{2}{c}{ Clay mineral content (\%) } \\
& Quartz & K-feldspar & Plagioclase & Calcspar & Dolomite & Siderite & Pyrite & (2) \\
\hline Granite & 27.0 & 37.0 & 31.0 & - & - & - & - & 5.0 \\
A-sandstone (a) & 57.7 & 8.7 & 13.8 & 0.5 & - & - & 1.5 & 17.8 \\
A-sandstone (b) & 23.4 & 4.6 & 3.0 & 22.5 & 5.1 & 20 & 0.9 & 20.5 \\
\hline
\end{tabular}

A-sandstone means the argillaceous sandstone. (a) and (b) are two samples used for the X-ray diffraction analysis, and the first one is lighter while the other one is darker.

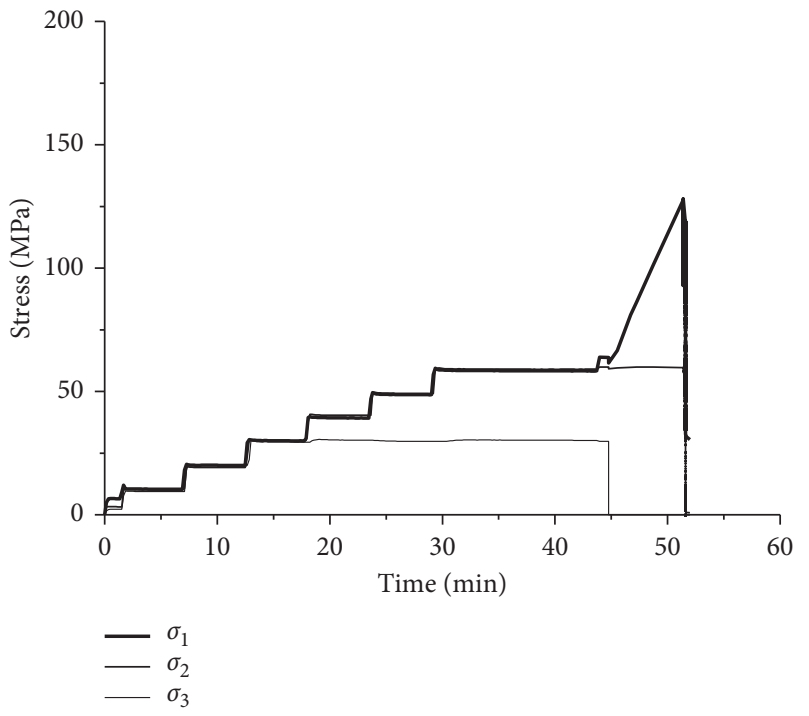

(a)

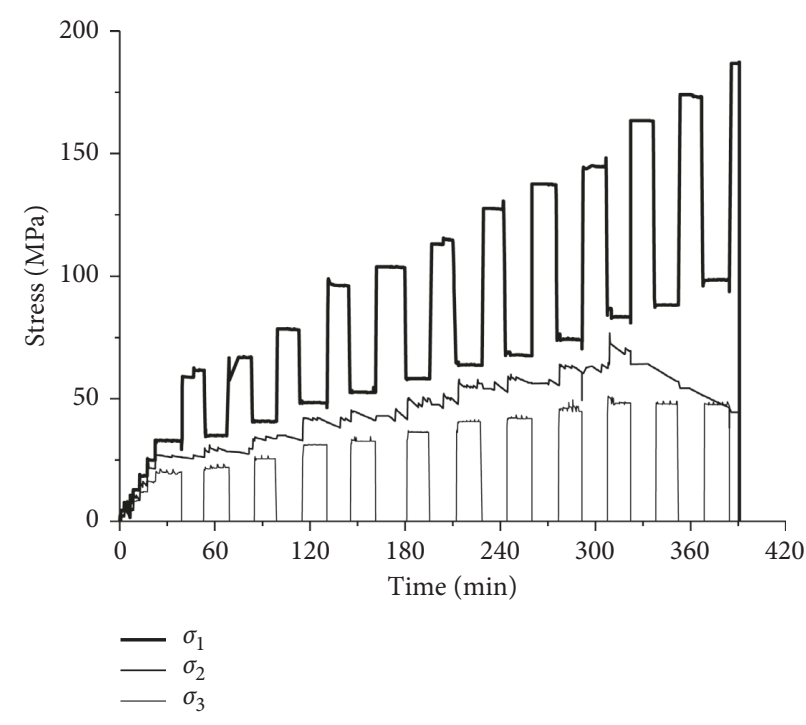

(b)

FIGURE 1: Stress-time curves of (a) granite and (b) argillaceous sandstone [22] in the laboratory strain burst experiments.
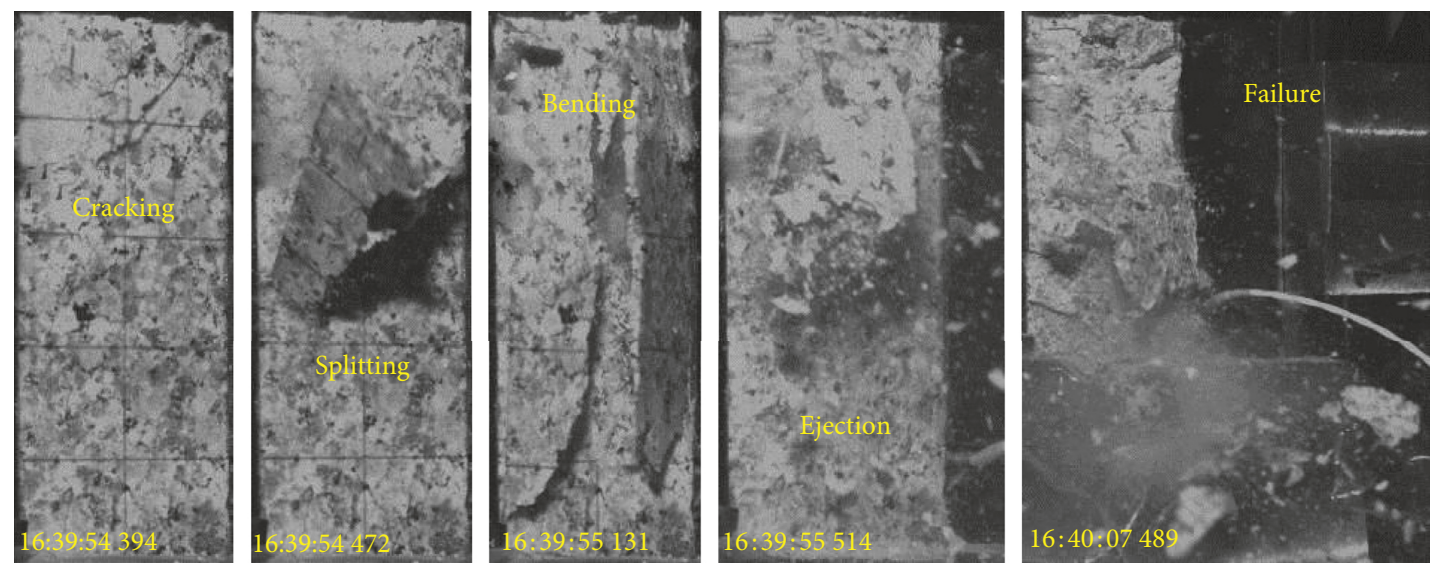

FIgURE 2: Failure process of the granite in the strain burst test captured by the high-speed camera. The number under each photograph shows the time (h:min:s $\mathrm{ms}$ ). 

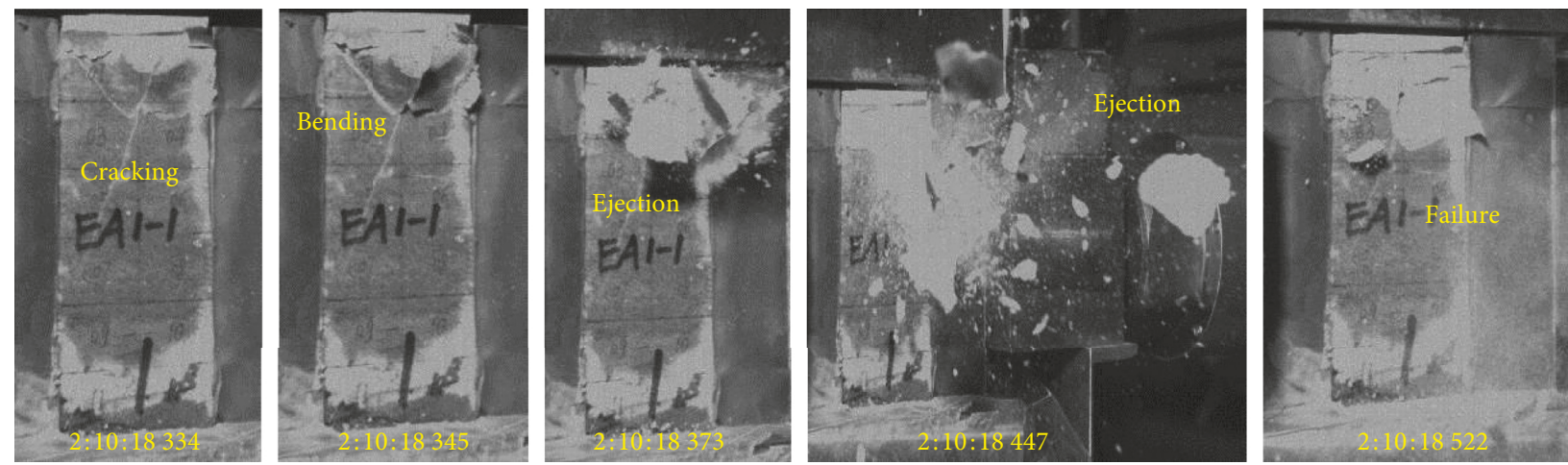

Figure 3: Failure process of the argillaceous sandstone in the strain burst test captured by the high-speed camera [22].
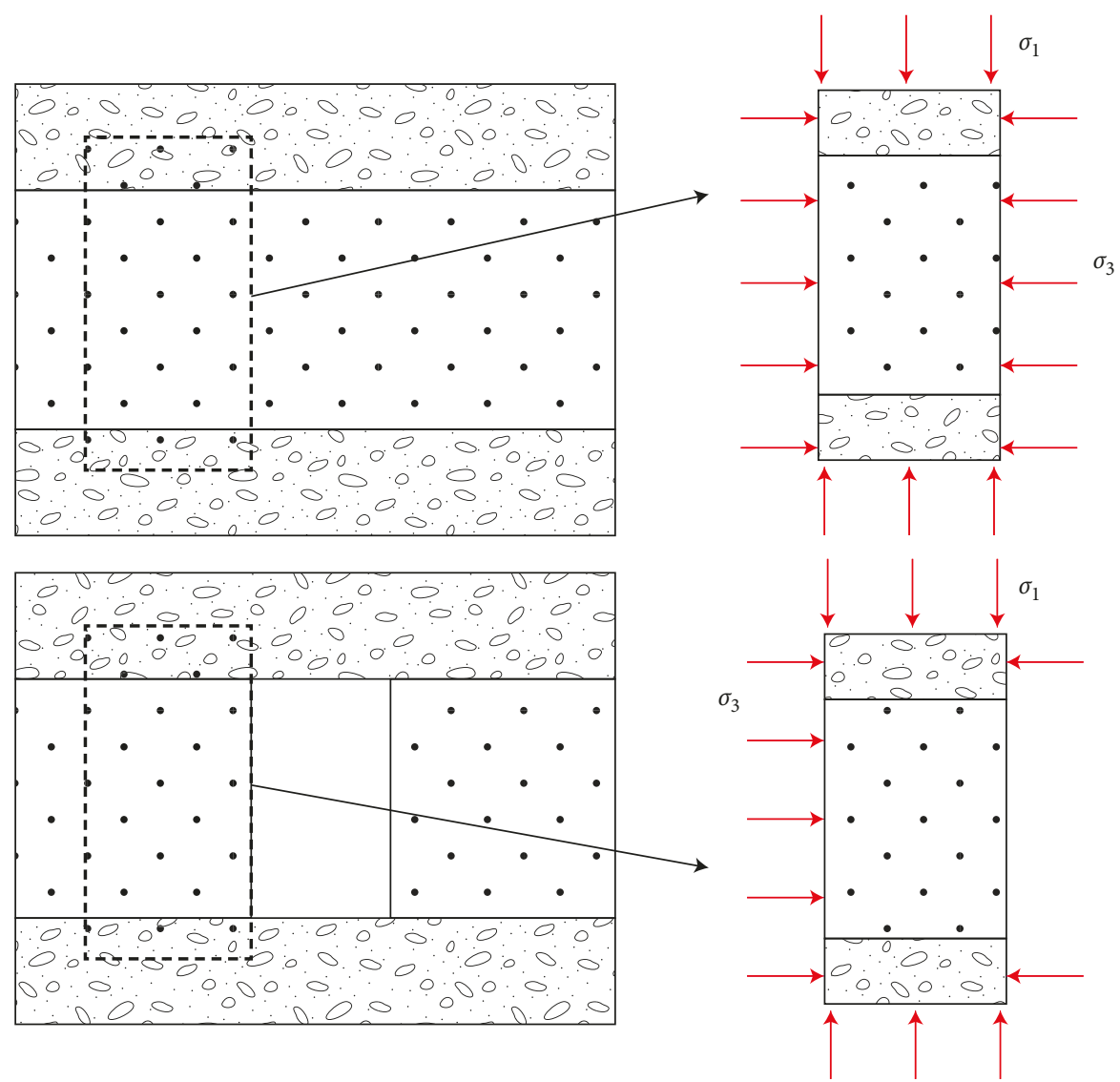

FIGURE 4: Schematic of the engineering geological model and engineering geomechanical model for strain burst considering different stiffness of the rock layers. The dashed rectangular frames in both graphs illustrate the zone including the excavation wall, roof, and floor that are discussed in this study.

displacement or motion, including rotation and complete separation. These features cannot be implemented in a continuous approach. Additionally, the main influence area of rock mass rupture is concentrated near the surface of tunnel or roadway. Therefore, the discontinuous method is more suitable for near-field rock mass simulation around excavated body, and the equivalent continuity method is more suitable for the far-field simulation.

The strain burst is a typical near-field rock mechanic and engineering problem; therefore, the discontinuous method is more suitable for the research needs of this paper. And the PFC (particle flow code) is one of the most popular discontinuous methods, which was developed by ITASCA. The bonded particle model (BPM) [24] is a basic model that is widely used in the particle flow program to simulate the mechanical properties of rock and soil. The basic unit of this model is a circular or spherical rigid body particle. These nonuniform scale particles are bonded together at their contact points to form assemblies, and the mechanical properties of the geological material are simulated by the mechanical behavior of the assemblies with certain properties. 
Many researchers [25-30] have used the BMP model to simulate the rock behaviors including elasticity, fracturing, acoustic emission, and damage accumulation producing material anisotropy, hysteresis, dilation, postpeak softening, and strength increase with confinement. What is more, the behavior of this model is based on the calibration of the microproperties of the particles and bonds which follow the basic Newton's law of motion instead of a prescribed constitutive model. Consequently, PFC is a good selection to study the strain burst behavior under various system stiffness.

3.2.2. Building and Calibration of Numerical Model. Similar to the geomechanical model in Figure 4, the numerical model is built as shown in Figure 5. The particle assemblies with different colors represent the roof (red), excavation wall (blue), and floor (red), respectively, with different stiffness by defining different contact moduli of the particles and parallel bond moduli.

A model with the dimension of $40 \mathrm{~mm} \times 100 \mathrm{~mm}$ is built and calibrated according to the physical and mechanical parameters of argillaceous sandstone. The calibrated microproperties are presented in Table 3 . The process of calibration is loaded by a pair of walls in the PFC program with a loading rate of $0.05 \mathrm{~m} / \mathrm{s}$, so this test is under an ideal stiff condition. The loading rate of $0.05 \mathrm{~m} / \mathrm{s}$ is not identical to that in the physical world, and Cho et al. [31] have explained that the time step in each calculation cycle is chosen to be infinitely small value; therefore, these physically unreasonably high loading rates are slow enough in the PFC analysis. The failure feature and the calculated stress-strain curve are shown in Figure 6, respectively. The calibrated specimen consists of 3427 balls and has a uniaxial compressive strength of 136.2 MPa, Young's modulus of $38.3 \mathrm{GPa}$, and Possion's ratio of 0.36 , and then the prepeak stiffness can be obtained as $0.01544 \mathrm{GN} / \mathrm{m}$ based on the size of the specimen (the thickness of this 2-dimensional model is assumed to be unity).

3.3. Numerical Tests on Strain Burst. Two-particle assemblies with the size of $40 \mathrm{~mm} \times 25 \mathrm{~mm}$ simulating the roof and floor are built at the top and bottom of the $40 \mathrm{~mm} \times 100 \mathrm{~mm}$ model of the excavation wall. The contact moduli of the particles and parallel bond moduli in the roof and floor models are given to be various values to simulate the conditions with different stiffness, while the normal and shear bond strengths of the bonds between the grains are set to be a quite high value to guarantee that failure only occurs in the excavation wall. The microparameters of the roof and floor in the strain burst model are listed in Table 4, while those for the excavation wall just use the parameters in Table 3. The interfaces between the roof/floor and the excavation wall use the joint model with 0 frictional coefficient and 0 cohesion [24]; however, the interfaces cannot be absolutely smooth due to the roughness of the models composed of assemblies of circular particles.

The in situ stress state is identified according to the fitted general far-field stress relationship at depth for North China by Tan and Sun [32] as shown below:
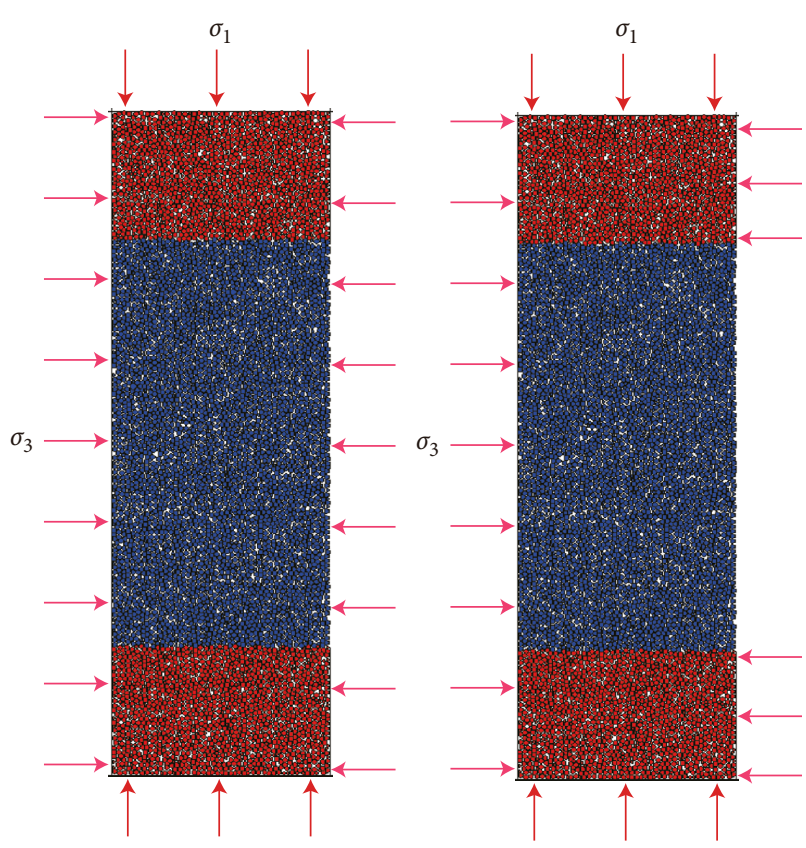

FIGURE 5: PFC model for strain burst.

TABle 3: Microparameters of the calibrated PFC model in the UC test and excavation wall model in the strain burst test.

\begin{tabular}{lccc}
\hline$E_{\mathrm{c}}, \overline{E_{\mathrm{c}}}$ & $48 \mathrm{GPa}$ & $R_{\min }$ & $0.42 \mathrm{~mm}$ \\
$k_{\mathrm{n}} / k_{\mathrm{s}}, \bar{k}_{\mathrm{n}} / \bar{k}_{\mathrm{s}}$ & 6.0 & $R_{\max } / R_{\min }$ & 1.66 \\
$\bar{\sigma}_{\mathrm{n}}$ & $110 \pm 27.5 \mathrm{MPa}$ & $\bar{\lambda}$ & 1.0 \\
$\bar{\sigma}_{\mathrm{s}}$ & $110 \pm 27.5 \mathrm{MPa}$ & $\mu$ & 0.5 \\
\hline
\end{tabular}

$$
\begin{aligned}
\sigma_{\mathrm{H}} & =0.02930 H+1.3548, \\
\sigma_{\mathrm{h}} & =0.01801 H+1.0018, \\
\sigma_{\mathrm{v}} & =0.02532 H+0.4177,
\end{aligned}
$$

where $\sigma_{\mathrm{H}}, \sigma_{\mathrm{h}}$, and $\sigma_{\mathrm{v}}$ are two horizontal in situ stresses and a vertical in situ stress, respectively, and $H$ is the depth.

Considering the mining depth of $1170 \mathrm{~m}$ [22], we obtain the in situ stress state of $\sigma_{1}=35.7 \mathrm{MPa}, \sigma_{2}=30.0 \mathrm{MPa}$, and $\sigma_{3}=22.1 \mathrm{MPa}$. We assume that $\sigma_{2}=30.0 \mathrm{MPa}$ is along the direction of opening. In the PFC model, the in situ stress state is applied biaxially ( $\sigma_{1}$ and $\sigma_{3}$ in this two-dimensional model) with the loading rate of $0.05 \mathrm{~m} / \mathrm{s}$ before one side of the excavation wall is unloaded abruptly. After the removing of the horizontal stress on one side which simulates the excavation, the stress concentration will occur in the vertical direction and the rate of concentration is set to be $0.2 \mathrm{~m} / \mathrm{s}$ in this study.

3.4. Definition of System Stiffness Ratio. The system of the PFC model in this study includes the excavation wall where strain burst may occur and the surrounding rock involving roof and floor, which is defined as "environment" in this paper. The stiffness ratio of the abovementioned two parts is employed here to describe the system stiffness. 


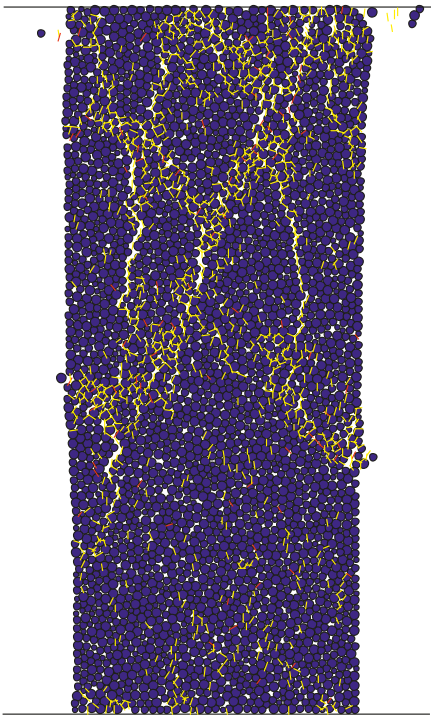

(a)

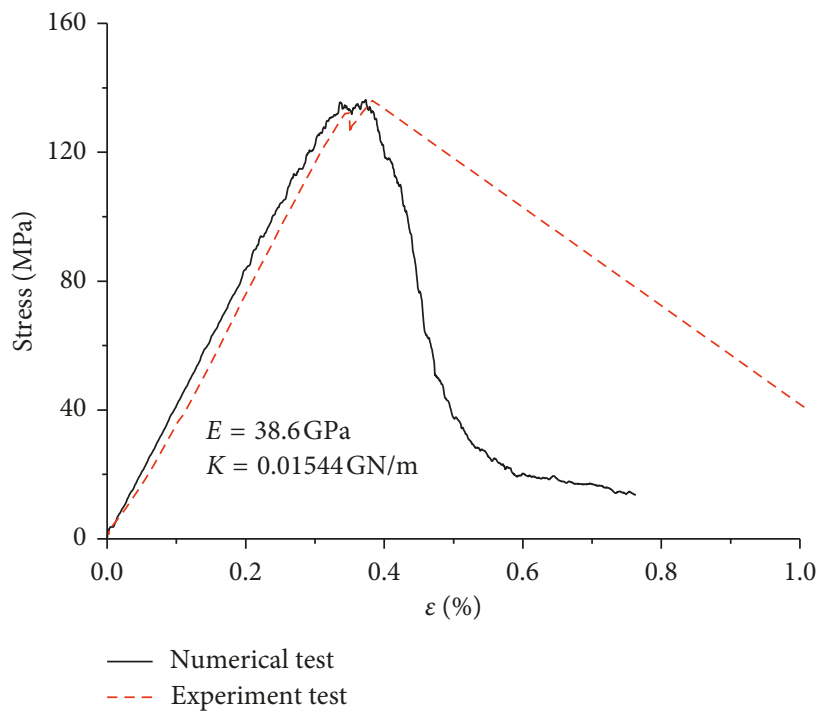

(b)

Figure 6: (a) Uniaxial compressive test on an intact specimen and (b) stress-strain curve for the intact rock and the calculated stiffness.

TABLe 4: Parameters in the PFC model for the roof and floor in the strain burst.

\begin{tabular}{lccc}
\hline$E_{\mathrm{c}}, \bar{E}_{\mathrm{c}}$ & Varies from 0.27 to $5000 \mathrm{GPa}$ & $R_{\min }$ & $0.42 \mathrm{~mm}$ \\
$k_{\mathrm{n}} / k_{\mathrm{s}}, \bar{k}_{\mathrm{n}} / \bar{k}_{\mathrm{s}}$ & 6.0 & $R_{\max } / R_{\min }$ & 1.66 \\
$\bar{\sigma}_{\mathrm{n}}$ & $1000000 \pm 0 \mathrm{MPa}$ & $\bar{\lambda}$ & 1.0 \\
$\bar{\sigma}_{\mathrm{s}}$ & $1000000 \pm 0 \mathrm{MPa}$ & $\mu$ & 0.5 \\
\hline
\end{tabular}

Note. $E_{\mathrm{c}}, \bar{E}_{\mathrm{c}}(\mathrm{GPa})$ of the roof and floor are set as $0.27,0.3,0.5,1,2,3,5,5.5$, $6,10,20,30,40,50,70,100,200,300,400,450,490,500,1000$, and 5000 in this series of studies.

As referred in Section 3.2, a series of various contact moduli of particles and parallel bond moduli are set in the roof and floor models. Based on a group of uniaxial compressive tests on these roof and floor models, their macro Young's moduli $E_{\mathrm{e}}$ can be obtained, and then their stiffness can be calculated as

$$
K_{\mathrm{e}}=\frac{A E}{l}
$$

where $A$ is the cross-sectional area of the sample (the thickness of this two-dimensional model is assumed to be unity) and $l$ is the length of the specimen along the axis of stress.

Young's modulus and stiffness of the excavation wall, denoted as $R_{\mathrm{E}}$ and $R_{\mathrm{K}}$, respectively, have been obtained in the calibration tests in Section 3.1. Hence Young's modulus ratio can be defined as

$$
R_{\mathrm{E}}=\frac{E_{\mathrm{e}}}{E_{\mathrm{r}}} .
$$

And similarly the system stiffness ratio can also be defined as

$$
R_{\mathrm{K}}=\frac{K_{\mathrm{e}}}{K_{\mathrm{r}}}
$$

\section{Numerical Test Results and Discussions}

4.1. Failure Characteristics. The calculated failure modes after excavation are demonstrated in Figure 7 . The numbers (e.g., 0.0082/0.0163) under each model are Young's modulus ratio $\left(R_{\mathrm{E}}\right)$ and stiffness ratio $\left(R_{\mathrm{K}}\right)$, respectively. It is obviously observed that the failure tend to be more violent with decreasing Young's modulus ratio and system stiffness ratio. The failure is quite violent in the scope from A to D1; buckling occurs on the unloading side of the excavation wall, and large blocks eject at high speed; from D2 to D4, fragment ejection can still be seen as well as the bulking; the failure turns to be less violent from D5 to F4, though there are still some small particle ejections and tensile cracks near the unloading face; from F5 to I, no ejection is observed and the localized shear is the main failure mode.

Based on the test results under different system stiffness, we can obtain the two critical Young's moduli ratios and stiffness ratios for this type of rock: (1) at point D4, Young's modulus ratio is 0.1368 and stiffness ratio is 0.2736 . If $R_{\mathrm{E}}$ and $R_{\mathrm{K}}$ are lower than this critical condition, the failure will be very violent with buckling and fragment ejections; (2) at point F4, Young's modulus ratio is 9.8870 and stiffness ratio is 19.7741 . If $R_{\mathrm{E}}$ and $R_{\mathrm{K}}$ are lower than this critical condition, the failure will be a little violent, and particle ejections will be observed. If the ratios are higher than this critical condition, the failure will be stable, and the main failure mode is shear. In this condition, the failure is just like the test result in a stiff test machine.

The failure processes in two typical tests are presented in Figures 8 and 9. Eight points are selected at 90\%, 80\%, 70\%, $60 \%, 50 \%, 40 \%, 30 \%$, and $20 \%$ of the peak stress in the postpeak region for each test in sequence. The processes show us very different crack propagation and failure characteristics under different system stiffness: 


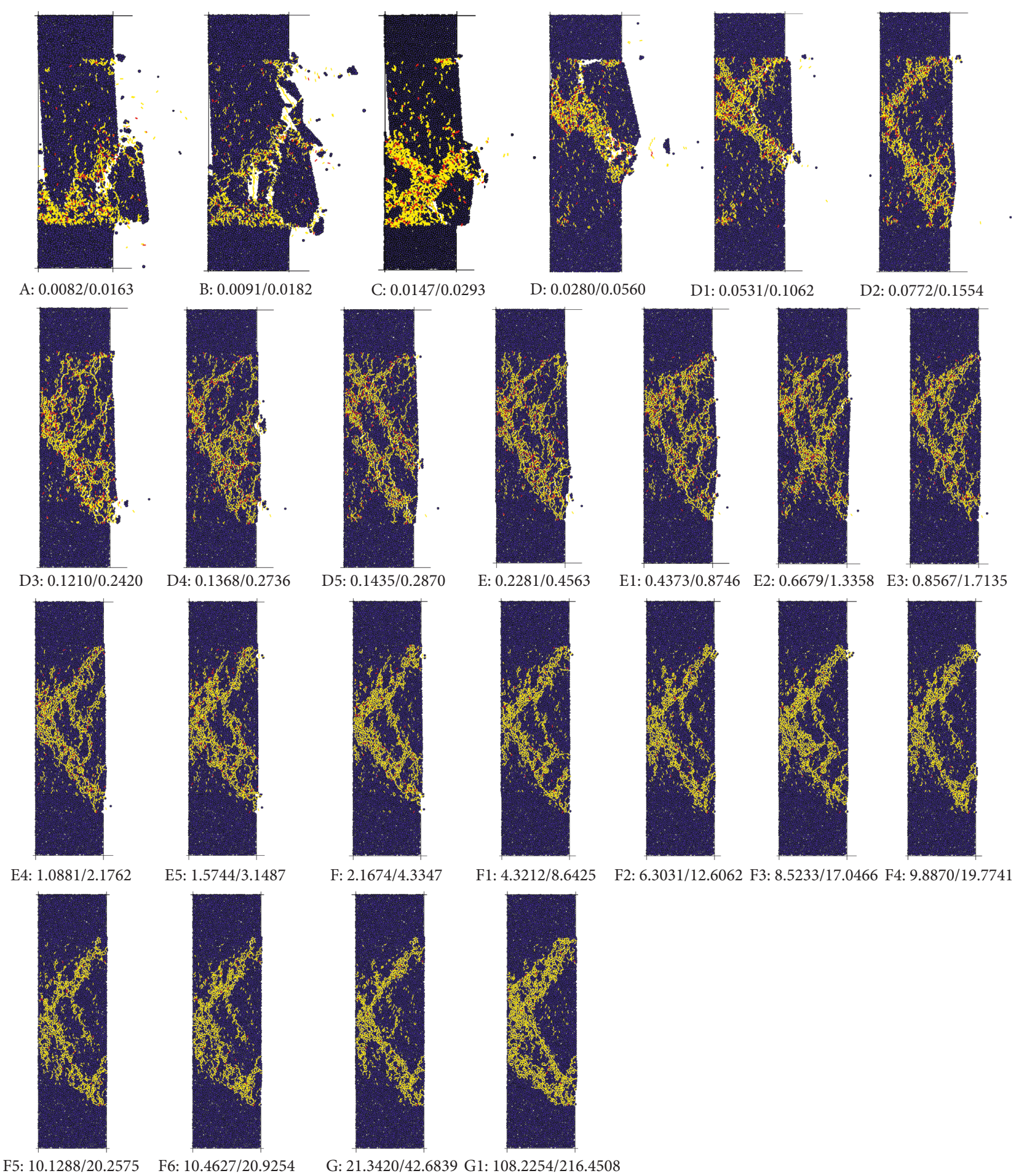

Figure 7: Failure modes and crack distribution after excavation in the PFC tests considering different system stiffness ratios. The numbers under each model are Young's modulus ratio $\left(R_{\mathrm{E}}\right)$ and stiffness ratio $\left(R_{\mathrm{K}}\right)$, respectively.

(1) For the softer condition $\left(R_{\mathrm{E}}=0.0091\right.$ and $\left.R_{\mathrm{K}}=0.0182\right)$ in Figure 8 , at the beginning period after unloading (Figures 8(a) and 8(b)), some weak zones suffered relatively severe damages and several particles and fragments ejected, but for the whole model, no localized failure planes formed except some dispersed microcracks. When the vertical stress went down to about $70 \%$ of the peak strength
(Figure 8(c)), vertical cracks coalescence formed and propagated very quickly and then spalling began. At about $40 \%$ of the peak strength (Figure $8(\mathrm{f})$ ), buckling began and fragments with different sizes started to fly out, and the unloading side of the excavation wall failed completely and violently. Tension-induced spalling and buckling are the main failure mechanism. 


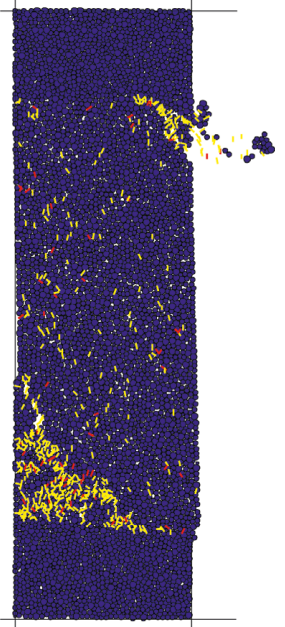

Step 609944

(a)

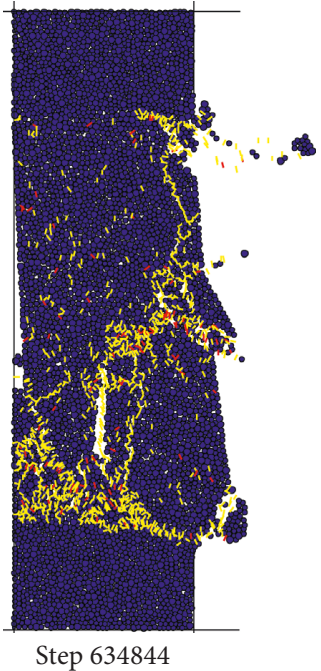

Step 634844

(e)

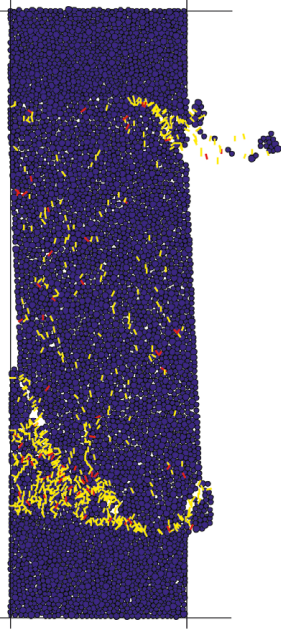

Step 617644

(b)

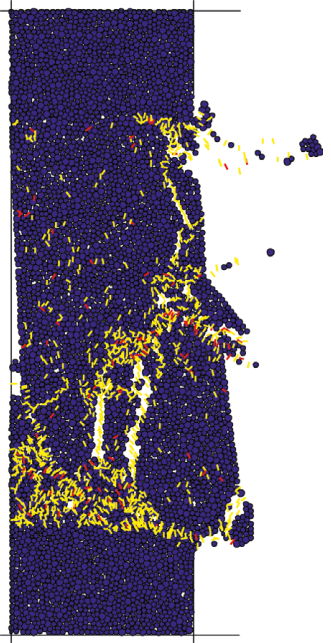

Step 639444

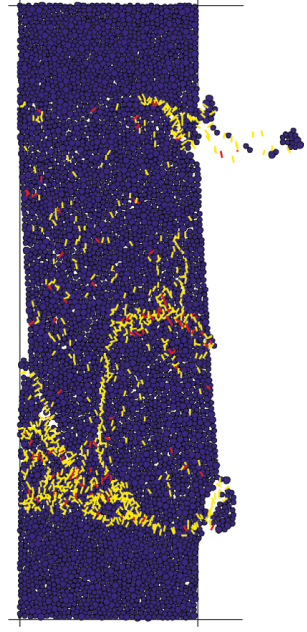

Step 624744

(c)

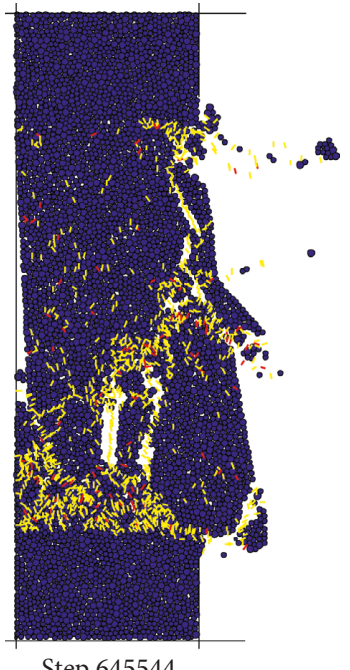

Step 645544

(g)

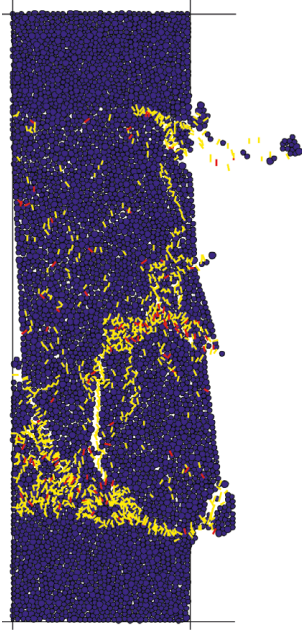

Step 629644

(d)

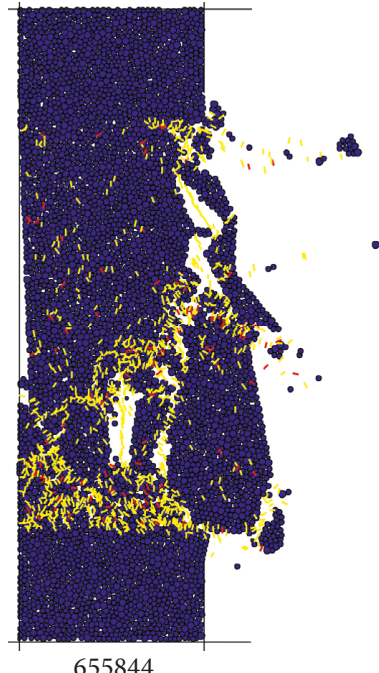

(h)

Figure 8: Failure process of ${ }^{\#} \mathrm{~B}$ strain burst test $\left(R_{\mathrm{E}}=0.0091\right.$ and $\left.R_{\mathrm{K}}=0.0182\right)$. (a) Step 609944. (b) Step 617644. (c) Step 624744. (d) Step 629644. (e) Step 634844. (f) Step 639444. (g) Step 645544. (h) Step 655844.

(2) For the stiffer condition $\left(R_{\mathrm{E}}=9.8870\right.$ and $\left.R_{\mathrm{K}}=19.7741\right)$ in Figure 9, when the vertical stress dropped to about $90 \%$ of the peak strength (Figure 9(a)), the shear planes almost formed, and the main failure mechanism in the whole process is shear. At about $20 \%$ of the peak strength (Figure 9(h)), only several small particle ejections can be observed.

The series of numerical tests prove that strain burst is not simply determined by the rock material itself but is related to the complete system. The study based on the stress and strength can only predict when the failure may happen rather than how violent it will be. The previous researches focused on the characteristics of the rock material like brittleness are also limited without considering the properties of the surrounding rock mass. In this study, if the environmental system is relatively softer, there will be more strain energy released from the roof and floor, and hence, the failure is prone to be more violent, while if the environmental system is relatively stiffer, less energy will be released and the failure will be more stable. In the next section, the energy release from the roof and floor will be calculated and analyzed to find out how does the system stiffness influence the violence of failure.

4.2. Energy Release from the Roof and Floor. During the numerical tests, two particle gauges lying at the central of the upper and lower edges of the roof and another two ones of the floor have been set to monitor their vertical strains. Figure 10 presents the vertical stress-strain curves of the roof and floor after unloading on one side of the excavation wall (the sizes of the roof and floor at the unloading point are considered as the original sizes, so their vertical strains at this point are 0 ). In the prepeak region, both the roof and floor are compressed and their vertical strains increase with 


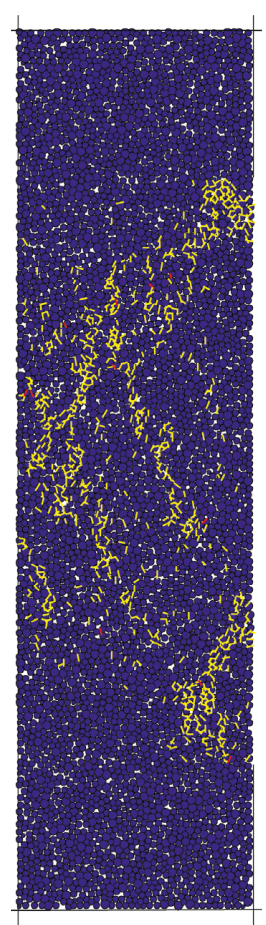

Step 49881

(a)

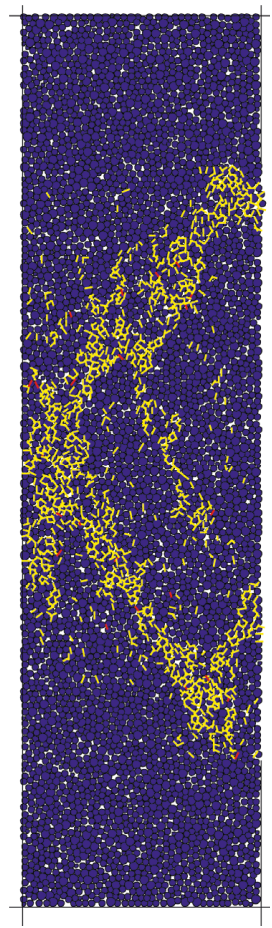

Step 56281

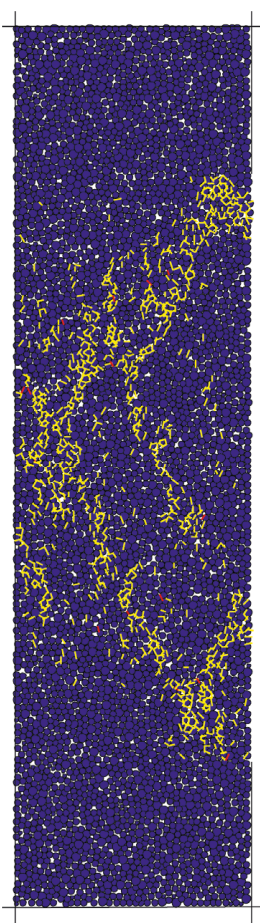

Step 51481

(b)

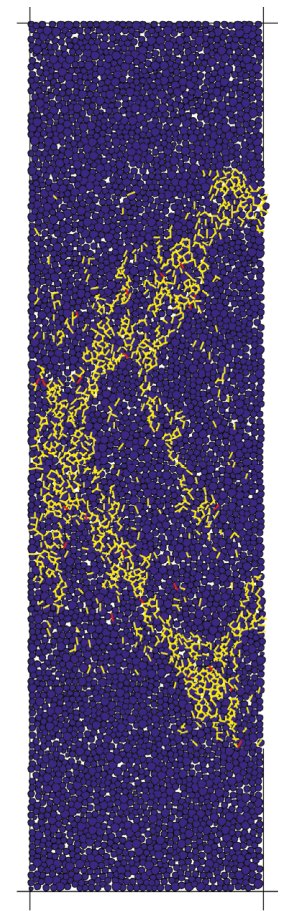

Step 57681

(f)

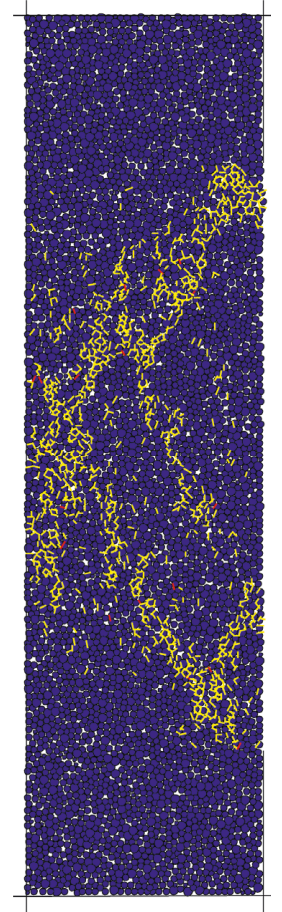

Step 52881

(c)

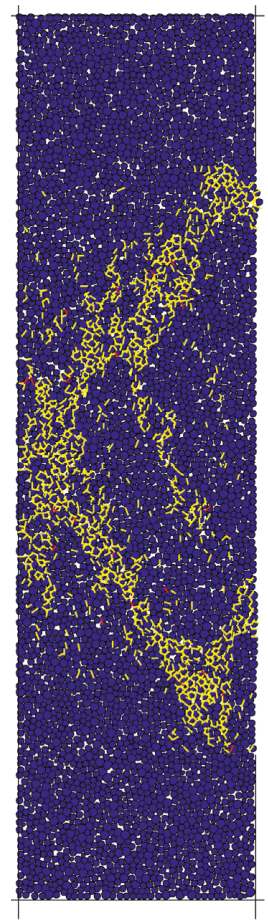

Step 60181

(g)

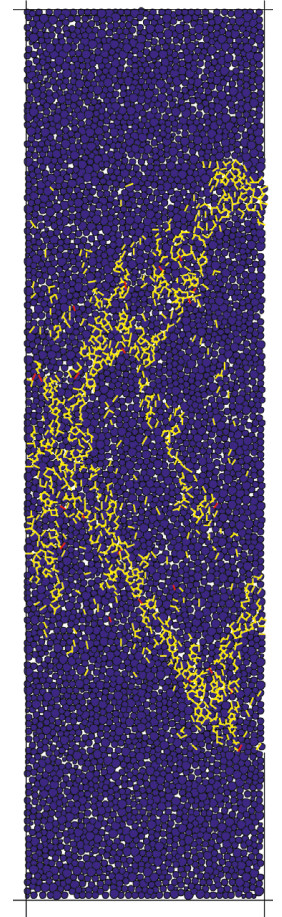

Step 54681

(d)

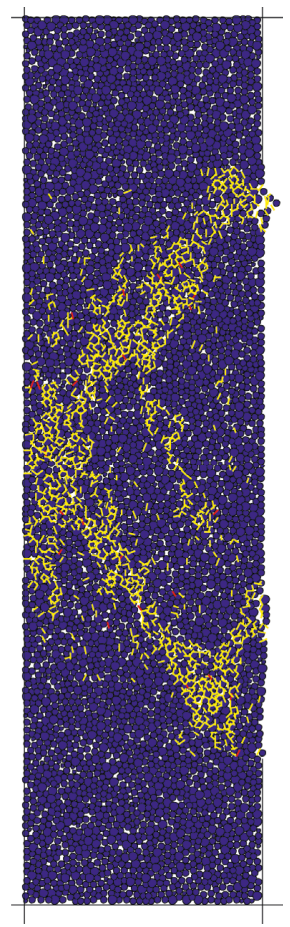

Step80181

(h)

Figure 9: Failure process of ${ }^{\#} \mathrm{~F} 4$ strain burst test $\left(R_{\mathrm{E}}=9.8870\right.$ and $\left.R_{\mathrm{K}}=19.7741\right)$. (a) Step 49881. (b) Step 51481. (c) Step 52881. (d) Step 54681. (e) Step 56281. (f) Step 57681. (g) Step 60181. (h) Step 80181.

the increasing vertical stress. With lower Young's moduli ratio and stiffness ratio, both the roof and floor show larger vertical strains. In the postpeak region, with the decreasing vertical stress, the roof and floor deform inversely and their vertical strains go down. It is observed that with lower Young's moduli ratio and stiffness ratio, the roof and floor also have larger inverse vertical strains, which are applied to the failing rock and induce larger strain and more violent 

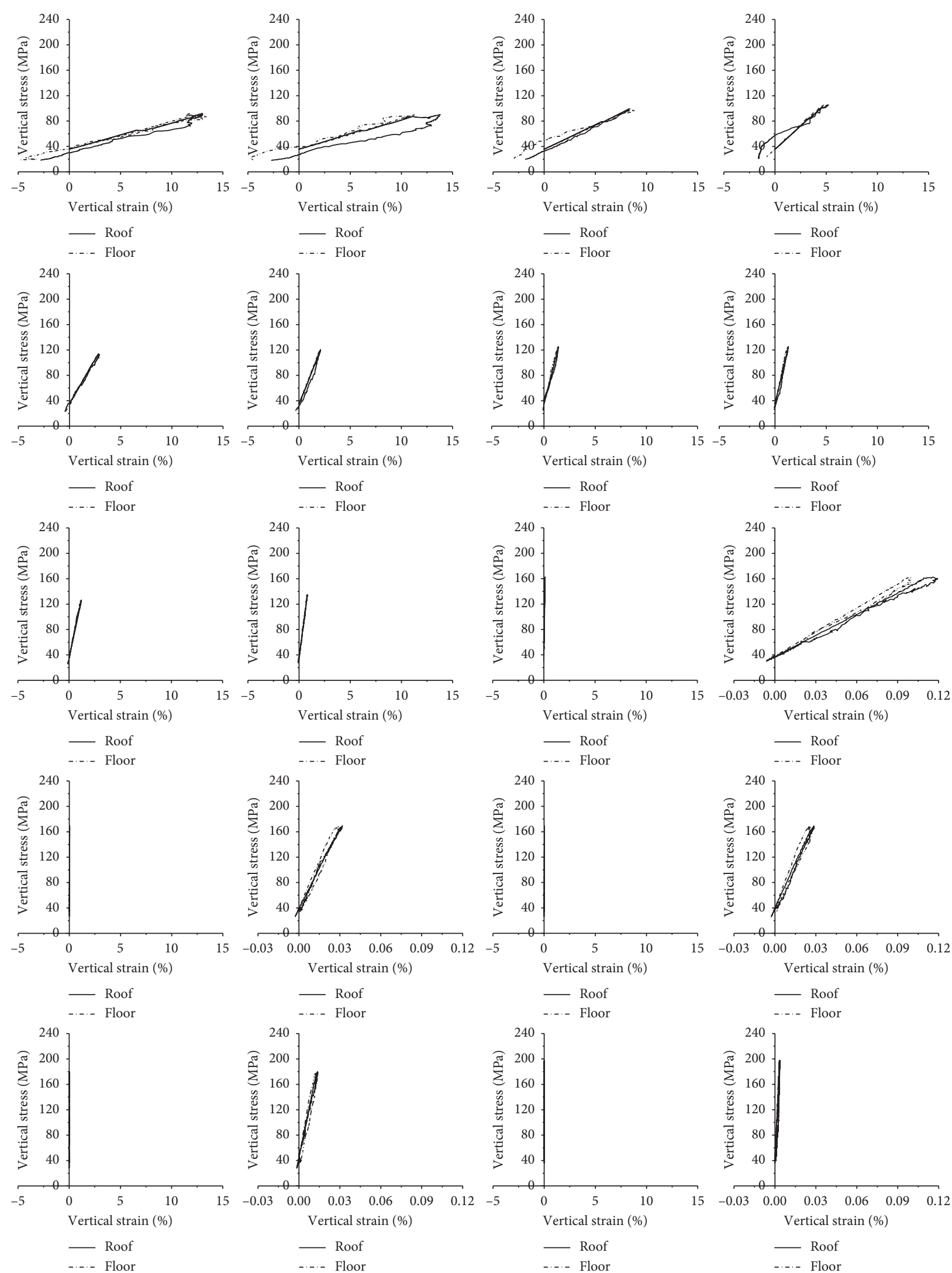

FIGURE 10: Vertical stress-strain curves of the roof and floor after unloading on one side of the excavation wall under various system stiffness. The two numbers under each graph are Young's modulus ratio $\left(R_{\mathrm{E}}\right)$ and stiffness ratio $\left(R_{\mathrm{K}}\right)$, respectively. The magnification of the last five graphs is also plotted due to the relatively small strains. 


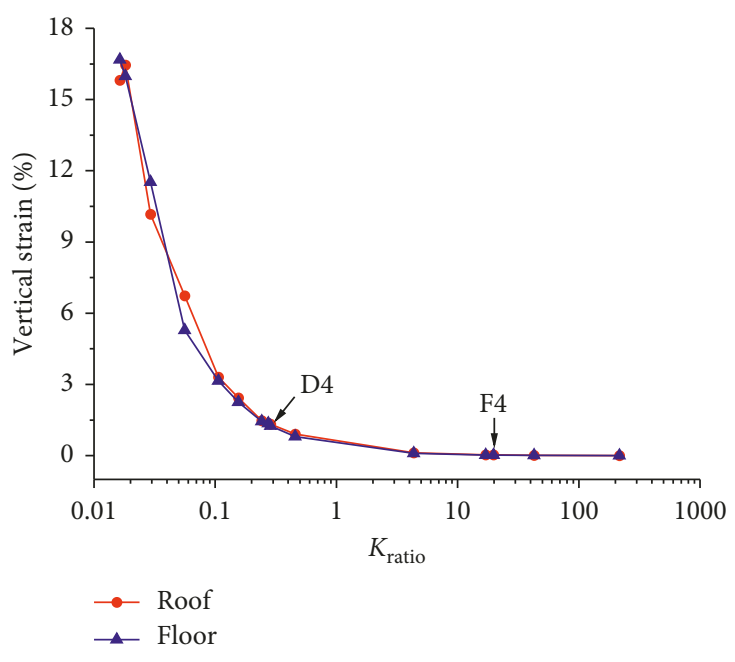

(a)

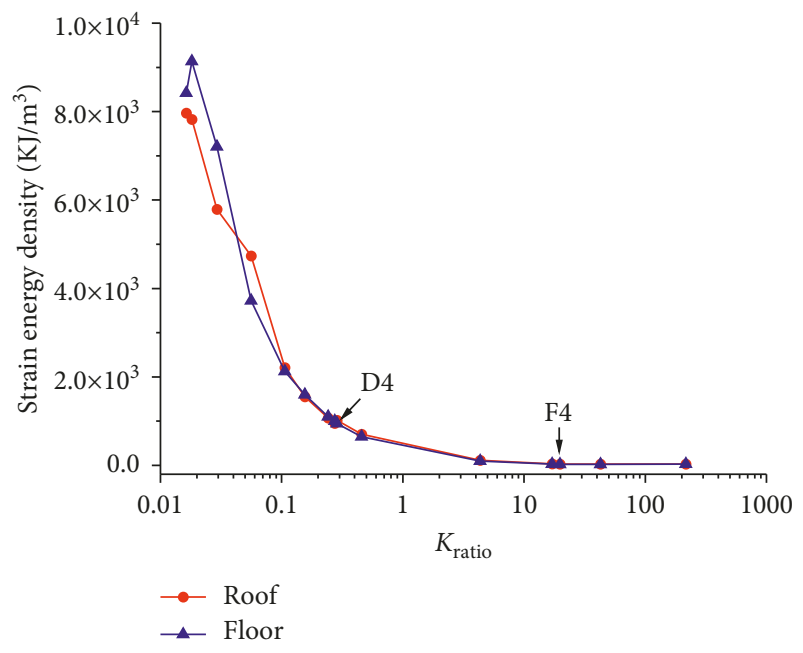

(b)

FigURE 11: (a) Relationship between the strain variation of roof and floor after peak strength and the system stiffness ratio $\left(R_{\mathrm{E}}\right)$. (b) Relationship between the strain energy densities of roof and floor after peak strength and the system stiffness ratio $\left(R_{\mathrm{K}}\right)$.

burst. The relationship between the vertical strains of the roof/floor and the stiffness ratio is plotted in Figure 11(a).

The areas below the vertical stress-strain curves of the roof and floor in the postpeak zone can be calculated with Microsoft Excel, and the areas represent the released strain energy density from the roof and floor in each numerical strain burst test. As the volume of each model is the same, the released strain energy density can be used to represent the energy release for comparison. The relationship between the released strain energy density and stiffness ratio is plotted in Figure 11(b), and the curves have the similar decreasing trend.

The two critical stiffness ratios are also pointed in Figures $11(\mathrm{a})$ and 11(b). When the stiffness ratio is lower than the first critical point, both the vertical strains and the released strain energy density of the roof and floor are quite high, decrease abruptly with the increasing stiffness ratio, and then go down gradually between the two critical points. When the stiffness ratio is higher than the second critical value, the vertical strains and released energy density turn almost constant, and the values are quite low. These observations can well explain the different failure modes in the three regions divided by the two critical stiffness ratios.

\section{Discussion}

The numerical tests prove that strain burst more likely occurs when the stiffness ratio is lower enough. In order to verify this view, some experiments were collected to calculate the stiffness ratios of each test. The main elements (as shown in Figure 12(a)) of the main machine contain reaction frame, hydrocylinder, loading rod, pressure head, and also include bearing platform in the vertical direction. Those elements were connected in series and parallel. Figure 12(b) shows the connection relationship of elements in the vertical direction. The element stiffness can be calculated by Equation (2). In addition, Equation (5) and (6) are the calculation formulas of system stiffness whose elements are connected in series and parallel, respectively:

$$
\begin{aligned}
K_{\text {series }} & =\frac{1}{\left(1 / K_{1}\right)+\left(1 / K_{2}\right)+\cdots+\left(1 / K_{n}\right)}, \\
K_{\text {parallel }} & =K_{1}+K_{2}+\cdots+K_{n},
\end{aligned}
$$

where $K$ is the stiffness, $A$ is the sectional area of element, $E$ is Young's modulus, and $l$ and $n$ are the length and number of element, respectively. During the stiffness calculation, the hydrocylinder was omitted because it was more complicated. So, the stiffness of the experiment system in the vertical direction is $0.54 \mathrm{GN} / \mathrm{m}$.

Table 5 lists some results of strain burst tests with different stiffness ratios. The intensity of strain burst was classified as four grades (strong, moderate, light, and no burst) according to the sound, failure phenomena [33]. Three key values $(0.85$, 1.18 , and 1.73) of stiffness ratio were determined. According to those key points, the axis of the stiffness ratio can be divided into four parts (I IV, as shown in Figure 13), which corresponds to the strong, moderate, light strain burst, and no burst, respectively. Additionally, if strain burst occurs, the strain energy released by the roof is larger than $347.2 \mathrm{~kJ} / \mathrm{m}^{3}$. Moreover, the statistical results of the experimental tests also show that strain burst more likely occurs when the stiffness ratio is lower enough (no more than 1.73).

However, the stiffness ratio of the critical point (D4: 0.27 ) is smaller than the key point (1.73) of experimental tests. The strain burst results are influenced by many factors, such as loading path, loading rate, specimen dimension, and internal structural, and some factors are difficult to keep unchanged; however, the numerical tests are consistent. Additionally, the stiffness of hydrocylinder is omitted during the stiffness calculation of the experiment system. Moreover, the experiment tests are three-dimensional while numerical 


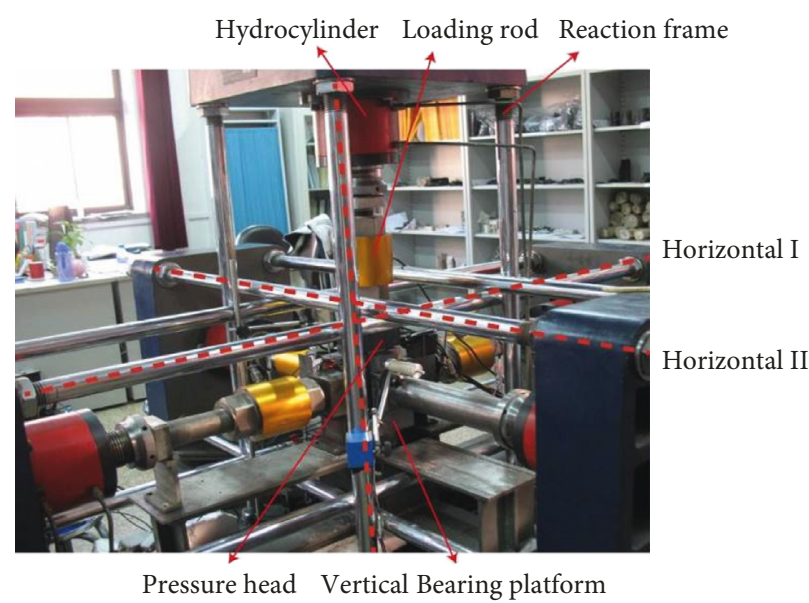

(a)

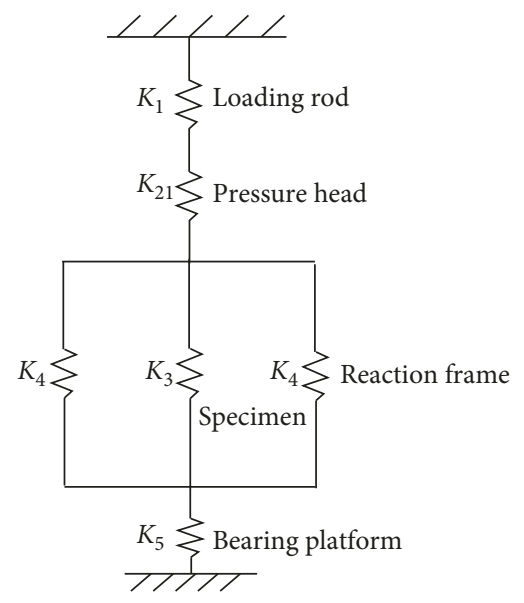

(b)

FIGURE 12: (a) Elements of the strain burst main machine [20] and (b) the schematic of the stiffness calculation in vertical direction.

TABLE 5: Results of strain burst tests for different specimens.

\begin{tabular}{|c|c|c|c|c|c|c|}
\hline Lithology & $\begin{array}{c}\text { Number of } \\
\text { tests }\end{array}$ & Sampling spots & $\begin{array}{c}\text { Mean Young's modulus } \\
(\mathrm{GPa})\end{array}$ & $\begin{array}{l}\text { Stiffness } \\
(\mathrm{GN} / \mathrm{m})\end{array}$ & $\begin{array}{l}\text { Stiffness } \\
\text { ratio }\end{array}$ & $\begin{array}{c}\text { Strain burst } \\
\text { intensity }\end{array}$ \\
\hline Peridotite & 2 & Garson mine & 60.1 & 0.72 & 0.75 & Strong \\
\hline Dolomite & 7 & Heishiling tunnel & 52.7 & 0.63 & 0.82 & Strong \\
\hline Granite & 20 & Laizhou & 51.0 & 0.61 & 0.85 & Strong \\
\hline Marble 1 & 13 & Jingpin II tunnel & 43.1 & 0.52 & 1.01 & Moderate \\
\hline Basalt & 3 & Baijiao coal mine & 42.8 & 0.51 & 1.01 & Moderate \\
\hline Sandstone & 8 & $\begin{array}{l}\text { Xingcun coal } \\
\text { mine }\end{array}$ & 39.1 & 0.47 & 1.11 & Moderate \\
\hline Limestone & 3 & Jiahe coal mine & 36.7 & 0.44 & 1.18 & Moderate \\
\hline Fine sandstone & 6 & $\begin{array}{l}\text { Antaibao coal } \\
\text { mine }\end{array}$ & 29.0 & 0.35 & 1.49 & Light \\
\hline Marble 2 & 7 & Jingpin I tunnel & 25.0 & 0.30 & 1.73 & Light \\
\hline $\begin{array}{l}\text { Sandy } \\
\text { mudstone }\end{array}$ & 4 & $\begin{array}{l}\text { Antaibao coal } \\
\text { mine }\end{array}$ & 22.9 & 0.27 & 1.89 & No burst \\
\hline Shale & 4 & Jiahe coal mine & 15.2 & 0.18 & 2.85 & No burst \\
\hline Slate & 4 & Tengchong tunnel & 13.5 & 0.16 & 3.21 & No burst \\
\hline
\end{tabular}

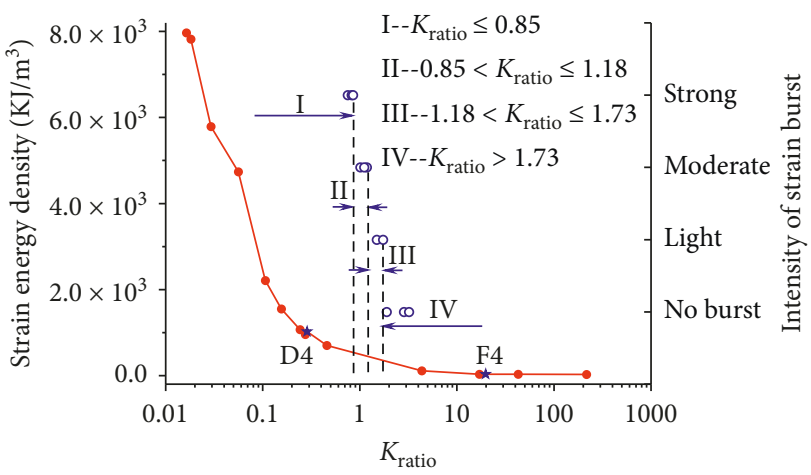

FIGURE 13: The comparison of the stiffness ratio obtained from the numerical and experimental tests, respectively.

tests are two-dimensional, which also leads to this gap. In the future, the three-dimensional numerical analysis of strain burst will be conducted.

\section{Conclusions}

Laboratory strain burst experiments are conducted to find the relationship between the failure mode and system stiffness. In order to further study this relationship quantificationally, engineering geological model, geomechanical model, and numerical model are built, respectively, and a series of strain burst tests have been carried out considering various system stiffness with the PFC (particle flow code) program. In this study, the whole system including the excavation wall as well as roof and floor is biaxially loaded to the in situ stress state, and then one side of the excavation wall is unloaded abruptly to simulate the excavation in the field. With various system stiffness determined by the microproperties of the contact moduli of the particles and parallel bond moduli in the models of roof and floor, the different failure characteristics are obtained. The conclusions can be drawn as follows:

(1) Strain burst is not simply determined by the rock material itself but is related to the complete system. If 
the system is softer, there will be more strain energy released from the roof and floor, and hence, the failure is prone to be more violent, while if the system is stiffer, less energy will be released and the failure will be more stable. Whether strain burst will occur is determined by the system stiffness ratio rather than the stress and strength, or simply the characteristics of the rock material itself like the burst proneness index or brittleness. Consequently, strain burst can not only happen in the hard brittle rock like granite but also happen in the relatively ductile rock-like argillaceous sandstone, if only the system stiffness ratio is low enough.

(2) Two critical Young's moduli ratios and stiffness ratios are identified. If the ratios are lower than the first critical condition, the failure will be very violent with buckling and fragment ejections. If the ratios are lower than the second critical condition, the failure will be a little violent, and particle ejections will be observed. If the ratios are higher than this critical condition, the failure will be stable, and the main failure mode is shear. In this condition, the failure is just like the test result in a stiff test machine.

(3) The vertical strains and released strain energy density of the roof and floor decrease with the increasing system stiffness ratio. Their relationship in the three zones divided by the two critical ratios accords well with the different failure modes under the corresponding system stiffness and can make a good explanation to the different severities of strain burst.

\section{Nomenclature}

$\begin{array}{ll}\sigma_{\mathrm{c}}, \sigma_{\mathrm{t}}, \varphi: \quad \begin{array}{l}\text { Uniaxial compressive and tensile strengths, } \\ \text { frictional angle of the rock }\end{array} \\ u_{1}, u_{2}: \quad \begin{array}{l}\text { Permanent and elastic axial deformation of the } \\ \text { rock specimen in a loading-unloading cycling } \\ \text { uniaxial test }\end{array} \\ K_{\mathrm{e}}, K_{\mathrm{r}}: \quad \begin{array}{l}\text { Stiffness of environment or surrounding and } \\ \text { excavation rock }\end{array} \\ E_{\mathrm{e}}, E_{\mathrm{r}}: \quad \begin{array}{l}\text { Young's moduli of environment or surrounding } \\ \text { and excavation rock }\end{array} \\ R_{\mathrm{E}}, R_{\mathrm{K}}: \quad \begin{array}{l}\text { Ratios of Young's modulus and stiffness between } \\ \text { environment and excavation rock }\end{array} \\ E_{\mathrm{c}}, \bar{E}_{\mathrm{c}}: \quad \begin{array}{l}\text { Contact modulus and parallel bond modulus } \\ \text { Contact SR (normal to shear) and parallel bond }\end{array} \\ k_{\mathrm{n}} / k_{\mathrm{s}}, & \begin{array}{l}\text { SR (normal to shear) } \\ \bar{k}_{\mathrm{n}} / \bar{k}_{\mathrm{s}}:\end{array} \\ \bar{\sigma}_{\mathrm{n}}: & \begin{array}{l}\text { Parallel normal bond strength } \\ \text { Parallel shear bond strength }\end{array} \\ \bar{\sigma}_{\mathrm{s}}: & \text { Minimum and maximum particle radii } \\ R_{\mathrm{min}}, & \text { Parallel bond radius ratio } \\ R_{\max }: & \text { Coefficient of friction. }\end{array}$

\section{Data Availability}

The data used to support the findings of this study are available from the corresponding author upon request.

\section{Conflicts of Interest}

The authors declare that they have no conflicts of interest.

\section{Acknowledgments}

Financial support from the National Key Research and Development Program (Grant No. 2016YFC0600901) and National Natural Science Foundation of China (Grant No. 51704298) are gratefully acknowledged.

\section{Supplementary Materials}

A file, named "Data.xlsx," is the raw data of Figures 1, 6(b), 10, and 11. Data of Figures 1(a) and 1(b) are the loading path, which contains four columns: time and three principal stresses $\left(\sigma_{1}, \sigma_{2}, \sigma_{3}\right)$. Data of Figure $6(\mathrm{~b})$ contain strain and stress, data of Figure 10 contain vertical strain and stress of roof and floor, and additionally, data of Figures 11(a) and 11(b) contain stiffness ratio and vertical strain of roof and floor. Moreover, other data supporting the conclusions are presented as photos or diagrams. (Supplementary Materials)

\section{References}

[1] Hoek, Practical Rock Engineering, 2007, http://www. rocscience.com/education/hoeks_corner.

[2] J. Zhang, B. Fu, Z. Li, S. Song, and Y. Shang, "Criterion and classification for strain mode rockbursts based on five-factor comprehensive method," in Proceedings of 12th ISRM International Congress on Rock Mechanics, Beijing, China, October 2011.

[3] G. R. Khanlari and Ghaderi, "Analysis of rock burst in critical section of second part of Karaj-Tehran water supply tunne," in Proceedings of ISGSR 2011, Munich, Germany, June 2011.

[4] S. P. Singh, "Burst energy release index," Rock Mechanics and Rock Engineering, vol. 21, no. 2, pp. 149-155, 1988.

[5] Y. Tan, "Rockbursting characteristics and structural effects of rock mass," Science China Chemistry, vol. 35, pp. 981-990, 1992.

[6] V. Hucka and B. Das, "Brittleness determination of rocks by different methods," International Journal of Rock Mechanics and Mining Sciences and Geomechanics Abstracts, vol. 11, no. 10, pp. 389-392, 1974.

[7] G. E. Andreev, Brittle Failure of Rock Materials: Test Results and Constitutive Models, CRC Press, Boca Raton, FL, USA, 1995.

[8] J. Handin, "Strength and ductility," Handbook of Physical Constants, Geological Society of America, Vol. 97, pp. 223-289, Boulder, CO, USA, 1966.

[9] N. G. W. Cook, "A note on rockbursts considered as a problem of stability," Journal of the South African Institute of Mining and Metallurgy, vol. 65, pp. 437-46, 1965.

[10] M. D. G. Salamon, "Stability, instability and design of pillar workings," International Journal of Rock Mechanics and Mining Sciences and Geomechanics Abstracts, vol. 7, no. 6, pp. 613-631, 1970.

[11] W. Blake, "Rock-burst mechanics," Quarterly of the Colorado School of Mines, vol. 67, p. 1, 1972.

[12] D. G. F. Hedley, "Rockburst handbook for Ontario hardrock mines," CANMET Special Report 92-1E (SP), Mining Research Laboratories, CANMET, 2002. 
[13] Aglawe and J. Prataprao, "Unstable and violent failure around underground openings in highly stressed ground," Ph.D. thesis, Queen's University, Kingston, ON, USA, 2000.

[14] B. H. G. Brady and E. T. Brown, "Energy changes and stability in underground mining: design applications of boundary element methods," Transactions of the Institution of Mining and Metallurgy, vol. 90, pp. 61-68, 1981.

[15] P. Kaiser, D. Tannant, and D. R. Mccreath, "Drift support in burst-prone ground," Proceedings of the National Academy of Sciences of the United States of America, vol. 72, pp. 38633867, 1996.

[16] A. N. Stavrogin and B. G. Tarasov, "Experimental physics and rock mechanics," American Psychologist, vol. 5, pp. 627-633, 2001.

[17] E. M. C. Kias, R. Gu, R. Garvey et al., Modeling Unstable Rock Failure During A Uniaxial Compressive Strength Test, Illinois Register, SanFrancisco, CA, USA, 2011.

[18] R. Simon, M. Aubertin, and H. S. Mitri, "Evaluation of rockburst potential in hard rock mines," in Proceedings of 97 th Annual General Meeting of CIM Rock Mechanics and Strata Control Session, pp. 257-266, Halifax, Nova Scotia, Canada, May 1995.

[19] P. K. Kaiser and C. A. Tang, "Numerical simulation of damage accumulation and seismic energy release during brittle rock failure-part II: rib pillar collapse," International Journal of Rock Mechanics and Mining Sciences, vol. 35, no. 2, pp. 123-134, 1998.

[20] M. He, J. Miao, and J. Feng, "Rock burst process of limestone and its acoustic emission characteristics under true-triaxial unloading conditions," International Journal of Rock Mechanics and Mining Sciences, vol. 47, no. 2, pp. 286-298, 2010.

[21] M. He, H. Xia, X. Jia, W. Gong, F. Zhao, and K. Liang, "Studies on classification, criteria and control of rockbursts," Journal of Rock Mechanics and Geotechnical Engineering, vol. 4, no. 2, pp. 97-114, 2012.

[22] M. C. He, W. Nie, Z. Y. Zhao, and W. Guo, "Experimental investigation of bedding plane orientation on the rockburst behavior of sandstone," Rock Mechanics and Rock Engineering, vol. 45, no. 3, pp. 311-326, 2012.

[23] L. Jing, "A review of techniques, advances and outstanding issues in numerical modelling for rock mechanics and rock engineering," International Journal of Rock Mechanics and Mining Sciences, vol. 40, no. 3, pp. 283-353, 2003.

[24] D. O. Potyondy and P. A. Cundall, "A bonded-particle model for rock," International Journal of Rock Mechanics and Mining Sciences, vol. 41, no. 8, pp. 1329-1364, 2004.

[25] M. S. Diederichs, P. K. Kaiser, and E. Eberhardt, "Damage initiation and propagation in hard rock during tunnelling and the influence of near-face stress rotation," International Journal of Rock Mechanics and Mining Sciences, vol. 41, no. 5, pp. 785-812, 2004.

[26] J. F. Hazzard and R. P. Young, "Simulating acoustic emissions in bonded-particle models of rock," International Journal of Rock Mechanics and Mining Sciences, vol. 37, no. 5, pp. 867-872, 2000.

[27] B. An and D. D. Tannant, "Discrete element method contact model for dynamic simulation of inelastic rock impact," Computers and Geosciences, vol. 33, no. 4, pp. 513-521, 2007.

[28] D. O. Potyondy, "Simulating stress corrosion with a bondedparticle model for rock," International Journal of Rock Mechanics and Mining Sciences, vol. 44, no. 5, pp. 677-691, 2007.

[29] T. S. Wanne and R. P. Young, "Bonded-particle modeling of thermally fractured granite," International Journal of Rock
Mechanics and Mining Sciences, vol. 45, no. 5, pp. 789-799, 2008.

[30] M. Cai, P. K. Kaiser, H. Morioka et al., "Flac/pfc coupled numerical simulation of ae in large-scale underground excavations," International Journal of Rock Mechanics and Mining Sciences, vol. 44, no. 4, pp. 550-564, 2007.

[31] N. Cho, C. D. Martin, and D. C. Sego, "A clumped particle model for rock," International Journal of Rock Mechanics and Mining Sciences, vol. 44, no. 7, pp. 997-1010, 2007.

[32] Y. Tan and C. Sun, "An analysis of present-day regional tectonic stress field and crustal movement trend in China," Journal Geomechanics, vol. 1, p. 12, 1995.

[33] G. Zhao, D. Wang, B. Gao, and S. Wang, "Modifying rock burst criteria based on observations in a division tunnel," Engineering Geology, vol. 216, pp. 153-160, 2016. 


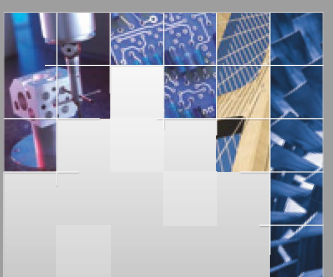

\section{Enfincering}
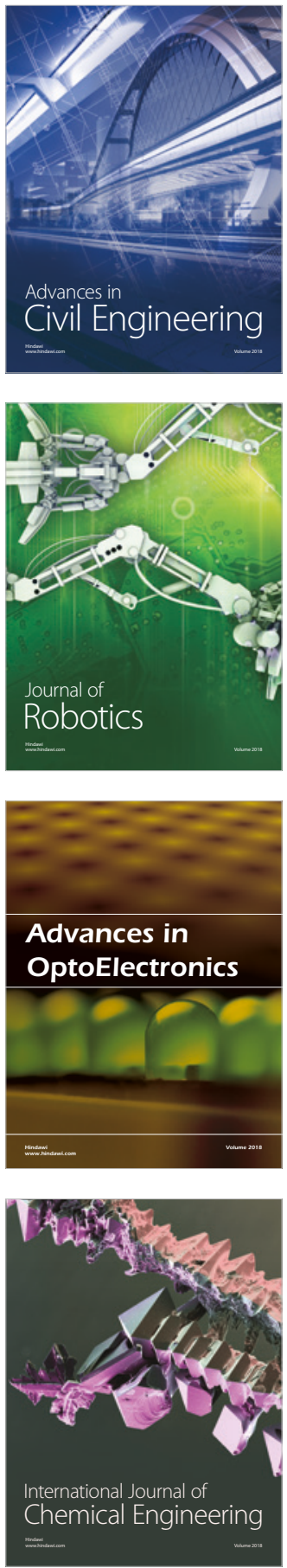

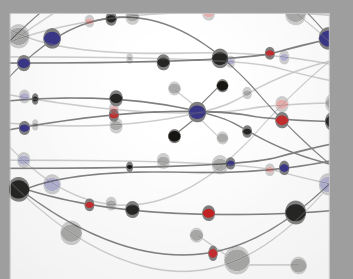

\section{Rotating \\ Machinery}

The Scientific World Journal

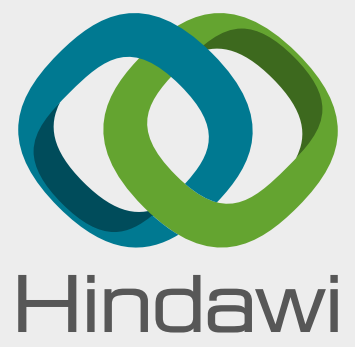

Submit your manuscripts at

www.hindawi.com
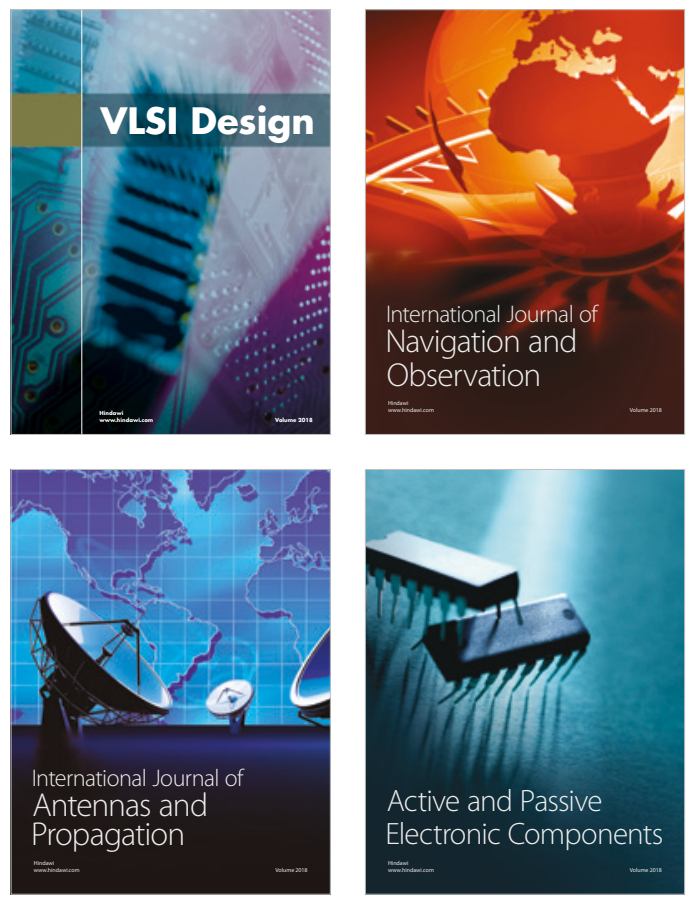
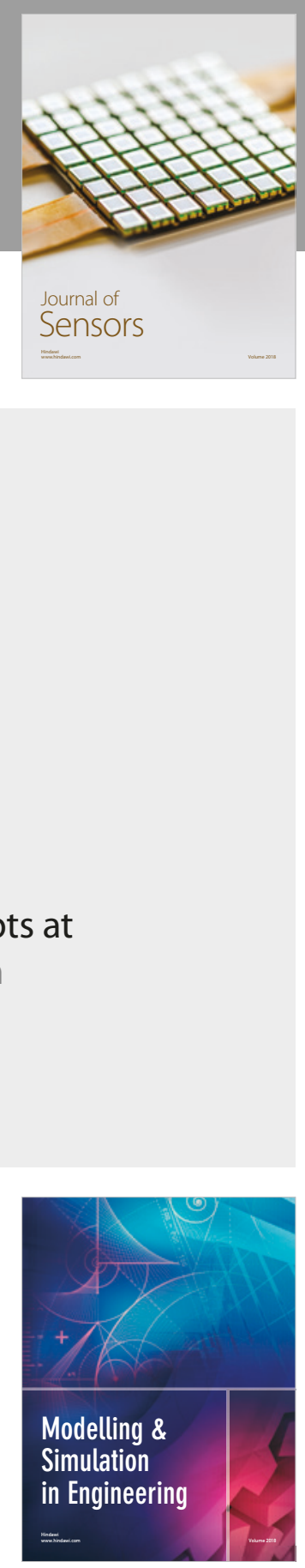

\section{Advances \\ Multimedia}
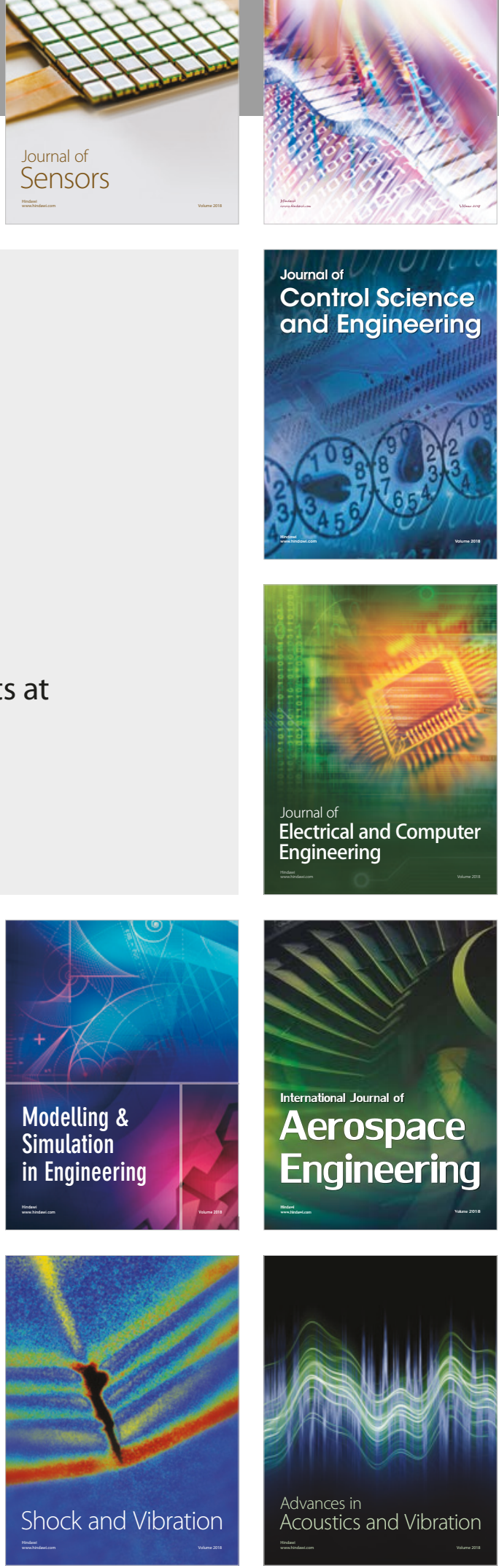